https://doi.org/10.26754/ojs_aem/aem.2017282538

Recibido: 22/01/2018

Aragón en la Edad Media

Aceptado: 09/03/2018

28 (2017) 221-253

e-ISSN: $2387-1377$

ISSN: 0213-2486

\title{
UN MANUSCRITO MEDIEVAL ARAGONÉS INÉDITO EN LA BIBLIOTECA DE UCLA: LA ORDENACIÓN DE LA COFRADÍA DE SAN JULIÁN DE TERUEL (BETA manid 5960)
}

\author{
A UNIQUE MEDIEVAL ARAGONESE MANUSCRIPT AT THE UCLA LIBRARY: \\ THE ORDENACIÓN DE LA COFRADÍA DE SAN JULIÁN DE TERUEL (BETA manid 5960)
}

\section{Óscar PEREA RODRÍGUEZ Proyecto PhiloBiblon}

Resumen: Este trabajo presenta el manuscrito 170/307 de la Charles Young Library de la Universidad de California en Los Ángeles (UCLA), catalogado pero inédito, que contiene las ordenanzas de una cofradía medieval prácticamente desconocida, ubicada en la ciudad de Teruel bajo la advocación de San Julián. La mayoría de los artículos fueron redactados en 1402, aunque tiene varios añadidos posteriores, del siglo $\mathrm{XV}$ y del siglo XVI. Se realiza la descripción codicológica del manuscrito de acuerdo a las normas de PhiloBiblon (BETA manid 5960) y se hace una edición comentada del texto, conforme a modernos criterios de edición.

Palabras clave: Charles Young Library, UCLA, codicología, cofradías, ordenanzas, PhiloBiblon, crítica textual, textos medievales.
Abstract: This paper describes a catalogued but rare manuscript (call number 170/307) held by the Charles Young Research Library at UCLA, in which one can find the by-laws of a barely known medieval confraternity, located in the city of Teruel and devoted to St. Julian. Most of these by-laws were written around 1402, although it does also include another group of them added later, during the $15^{\text {th }}$ and the $16^{\text {th }}$ centuries. The paper also contains the codicological description of the source according to PhiloBiblon standards (BETA manid 5960), together with a commented edition of the text based on modern textual criticism.

Key words: Charles Young Library, UCLA, codicology, confraternities, bylaws, PhiloBiblon, textual criticism, medieval texts. 


\section{El manuscrito de la Ordenación de la Cofradía de San Julián de Teruel ${ }^{1}$}

La Charles E. Young Research Library de la Universidad de California en Los Ángeles (más conocida por el acrónimo UCLA) posee un códice que, si bien no puede ser calificado como desconocido, pues su catalogación data de 1991, ${ }^{2}$ sí se puede decir que ha pasado totalmente desapercibido en el ámbito académico del medievalismo hispánico. Me estoy refiriendo a la Ordenación de la cofradía de San Julián de Teruel, manuscrito conservado en la citada biblioteca norteamericana con la signatura 170/307. ${ }^{3}$

El códice reposa en las baldas californianas desde el año $1963,{ }^{4}$ cuando fue comprado en España tal vez al mismo Ángel Sangros cuyo ex-libris figura en la portada como antiguo dueño, a la derecha de la anotación «Códice original» y una cifra que parece ser ' 1518 '. El otro elemento destacable de los folios iniciales del códice es el dibujo, a lápiz, del escudo de la cofradía, en el que aparecen mencionados los tres principales santos a cuya advocación estuvo dedicada la vida en hermandad de los miembros de esta agrupación: San Julián, San Bartolomé y Santa Quiteria. El tipo de letra utilizado y la iconografía de este grabado parecen indicar que fue dibujado allí con bastante posterioridad a la redacción de los estatutos, puesto que, en términos de estilo, el escudo se asemeja más a los típicos de finales del siglo Xvi, que es también la última fase de redacción de las ordenanzas contenidas en este manuscrito.

No hay otros indicios iconográficos que nos lleven a pensar que el códice fue confeccionado para otros motivos que no fueran de tipo práctico, es decir, para recoger las ordenanzas de la cofradía. Por lo tanto, no es un manuscrito de lujo sino uno de tipo convencional, pues, al margen del grabado ya visto, tan solo el folio inicial del texto presenta otros elementos llamativos, en este

1 Este trabajo forma parte del proyecto de investigación Identidades, contactos, afinidades: la espiritualidad en la península ibérica (siglos XII-XV), financiado por la DIGICYT (HAR201345199-R) y dirigido por la Dra. Isabel Beceiro Pita (CCHS-CSIC). Todos los datos obtenidos en esta investigación se encuentran disponibles en el proyecto PhiloBiblon - BETA: Bibliografía Española de Textos Antiguos, de libre acceso en Internet a través de la siguiente ruta: <http://bancroft.berkeley.edu/ philobiblon/> [2017-11-15]. Utilizo los identificadores de textos (texid) y de manuscritos (manid) de esta base de datos para la localización de fuentes mencionadas.

2 Mirella Ferrari, Medieval and Renaissance Manuscripts at the University of California, Los Angeles, ed. R. H. Rouse, Berkeley-Los Ángeles-Oxford, University of California Press, 1991, pp. 61-62.

3 En la página 17 se halla lo que podría ser una signatura antigua: «anagri 4.02.7».

4 Ferrari, 1991: 62. 
caso una inicial iluminada y motivos decorativos vegetales en la parte inferior del mismo. Ambos detalles se pueden ver en la imagen siguiente, en la cual también se muestra la alternancia de colores típica del códice, los títulos de capítulos y ordenanzas en tinta roja, mientras que la tinta oscura es la preferida para el texto principal.
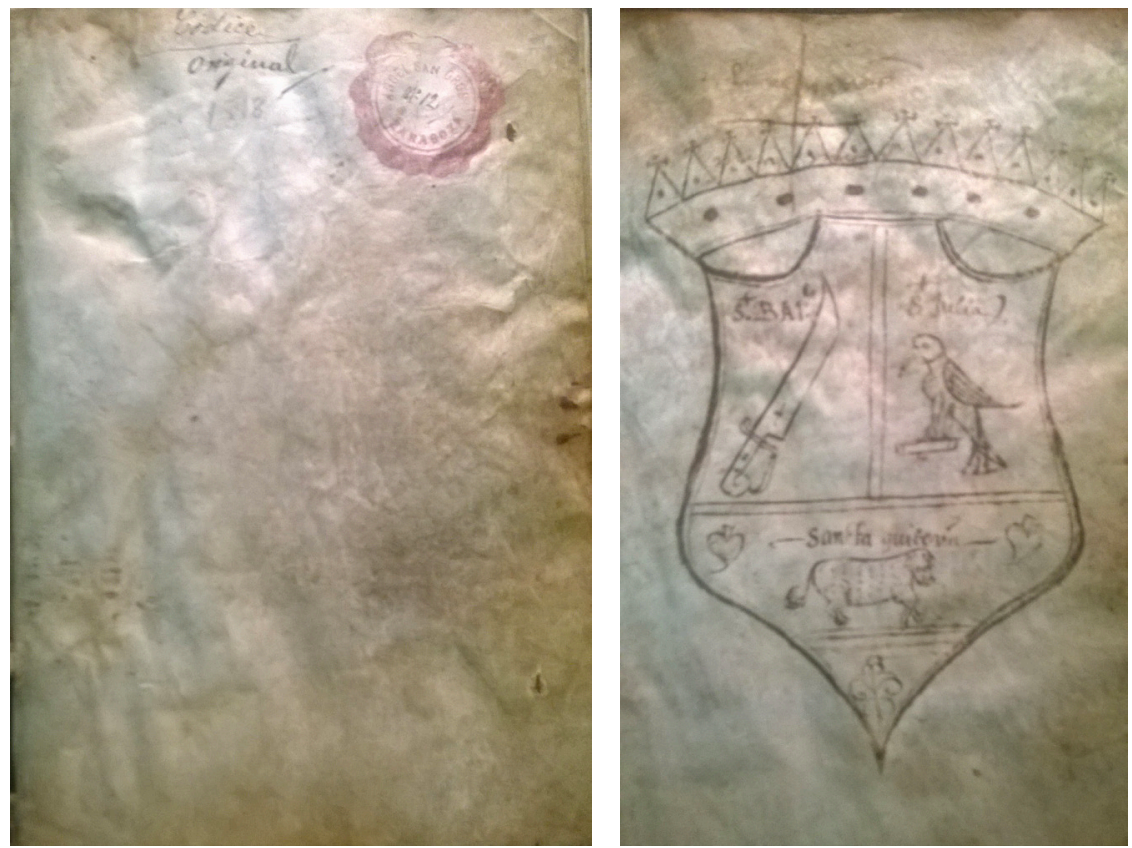

Figuras 1 y 2. Portada y primer folio del manuscrito, ambos en pergamino.

Otra de las características básicas del códice es que presenta una doble numeración en varias de sus hojas. Para empezar, todos los folios están paginados del 1 al 115 en números arábigos, con letra y tinta del siglo xx. Además, en el número 17 de esta paginación moderna encontramos el primer resto de la foliación original del códice, en números romanos, y que se extiende desde aquí hasta el final del mismo (Ir-Lr). En la edición del texto haremos referencia a esta doble numeración cuando así sea posible, con el fin de facilitar la consulta del original a cualquiera que estuviese interesado en hacerlo.

En términos materiales, el manuscrito es de pergamino, tanto los folios como la encuadernación, de tamaño cuarto. El número de líneas escritas en cada folio oscila entre las 13 (51/XVIIIr) y las 22 (111/XXXXVIIIr). Las demás medidas quedan sintetizadas en la tabla siguiente: 


\begin{tabular}{|l|l|l|l|}
\hline & Altura $(\mathrm{mm})$ & Anchura $(\mathrm{mm})$ & Páginas / Folios \\
\hline Encuadernación & 190 & 133 & \\
\hline Hoja & 188 & 133 & $51 /$ XVIIIr \\
\hline Caja de escritura & 125 & 89 & $51 /$ XVIIIr \\
\hline Hoja & 188 & 132 & $111 /$ XXXXVIIIr \\
\hline Caja de escritura & 138 & 99 & $111 /$ XXXXVIIIr \\
\hline
\end{tabular}

Un aspecto fundamental a tratar en la descripción del códice es la existencia de diversas manos de diferentes copistas, correspondientes a otras tantas épocas en las que se fueron añadiendo capítulos y ordenaciones posteriores a la fecha de su primigenia redacción. A través de este esquema el lector obtendrá una mejor idea de todo este entramado de fechas y escribas.

\begin{tabular}{|l|l|l|l|}
\hline Copista & Tipo de letra & Páginas / Folios & Año \\
\hline Mano A & gótica aragonesa & $1-11$ & 1402 \\
\hline Mano F & humanística redonda & $12-14$ & 1557 \\
\hline Mano A & gótica aragonesa & $17 / I r-68 / X X V I v$ & 1402 \\
\hline Mano B & gótica libraria & $68 / X X V I v-109 / X L V I I r$ & 1503 \\
\hline Mano C & humanística cursiva & $110 / X L V I I v$ & $1503-1524$ \\
\hline Mano D & humanística cursiva & $110 / X L V I I v-111 / X L V I I I r$ & 1529 \\
\hline Mano E & humanística cursiva & $112 / X L V I I I v$ & 1551 \\
\hline Mano F & humanística redonda & $113 / X L I X r$ & 1557 \\
\hline Mano G & humanística cursiva & $114 / X L I X v-115 / L r$ & 1574 \\
\hline
\end{tabular}

A la vista del cuadro, parece claro que la redacción original de la obra comenzó en 1402, y que se dejaron a propósito varios folios en blanco después del índice inicial, confeccionado ese mismo año. Casi todas las ordenanzas (42 de un total de 67 conservadas en el manuscrito) fueron copiadas y concertadas en el año 1402; entre 1503 y 1523 se añadieron 20 más, mientras que las 5 últimas se añadieron una por año, cada una de las posteriores manos del manuscrito, en los años 1524, 1529, 1551, 1557 y 1574. El copista de 1557 (mano F) añadió también varios capítulos al índice que se comenzó en 1402 , además de algunas anotaciones marginales de gran valor, pues a veces sirven para explicar diferencias entre los pagos de multas exigidos en unas épocas y otras. 


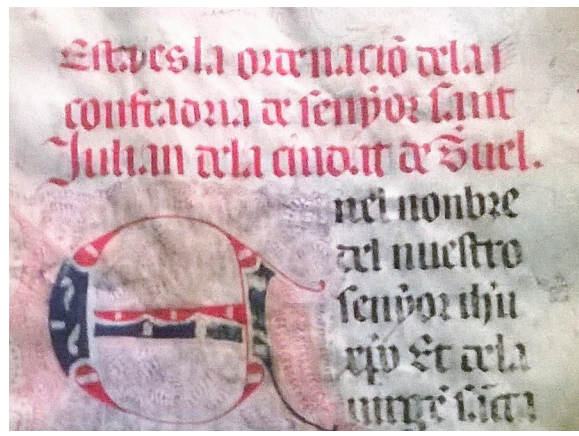

Fig. 3. Mano A (f. 1r).

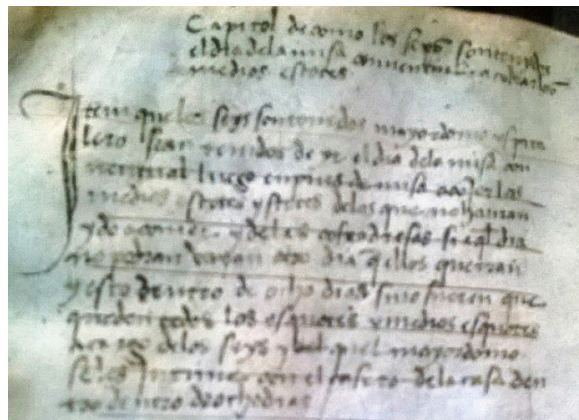

Fig. 5. Mano C (f. 47v).

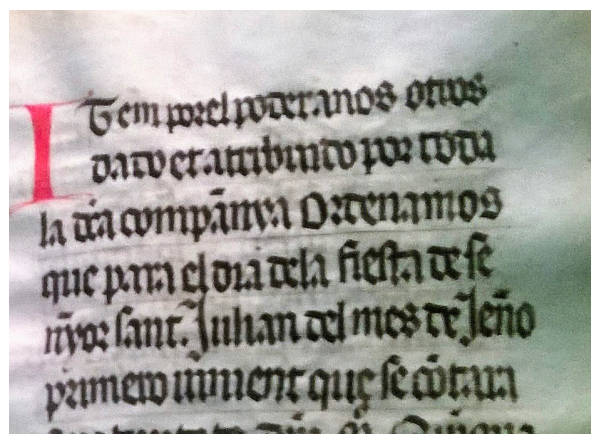

Fig. 4. Mano B (f. 29r).

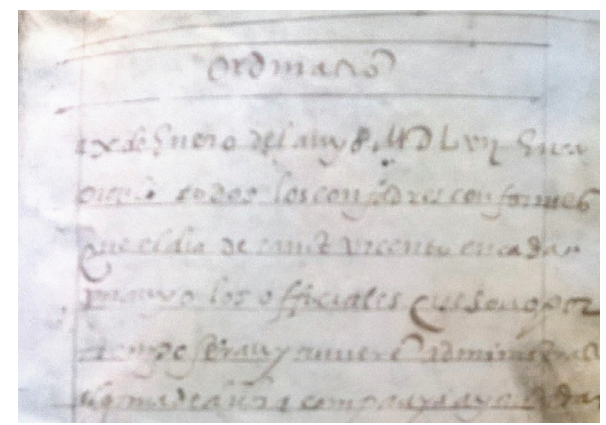

Fig. 6. Mano F (f. 49r).

La cofradía de San Julián, la turolense, ${ }^{5}$ no aparece mencionada en los exhaustivos recuentos de tales instituciones efectuados por Navarro Espinach para la Edad Media hispánica, ${ }^{6}$ y por Tello Hernández para las del reino de Aragón, ${ }^{7}$ como tampoco lo está en el trabajo de Pérez Pérez sobre las documentadas en Teruel, ${ }^{8}$ si bien casi todos los aspectos cotidianos y espirituales que se comentan en este estudio respecto a otras cofradías turolenses casan muy bien

5 No hay que confundirla con la homónima de pescadores zaragozana creada bajo la advocación del mismo santo, de la que se conocen datos de finales del siglo xv. Cf. María Isabel Falcón Pérez, Ordenanzas y otros documentos complementarios relativos a las corporaciones de oficio en el reino de Aragón en la Edad Media, Zaragoza, Institución «Fernando el Católico», 1997, pp. 238 y 541.

6 Germán Navarro Espinach, «Las cofradías medievales en España», Historia 396, 4.1 (2014), pp. $107-$ 133.

7 Esther Tello Hernández, Aportación al estudio de las cofradías medievales y sus devociones en el reino de Aragón, Zaragoza, Institución «Fernando el Católico», 2013.

8 Isabel Pérez Pérez, «Las cofradías religiosas en la diócesis de Teruel», Revista de Historia Jerónimo Zurita, 83 (2008), pp. 161-198. 
con el contenido de estas ordenanzas. Sí parece que se conocía la existencia del hospital asociado, al menos desde $1348,{ }^{9}$ y que todavía continuaba existiendo en $1529,{ }^{10}$ pero las menciones que hemos conservado son muy escasas en la documentación aragonesa de la que disponemos. Todos estos factores hacen muy atractivo el análisis profundo de estas ordenanzas, para poder solventar de forma conveniente todas las incógnitas que hoy día presenta el estudio de esta enigmática cofradía aragonesa medieval. Por ello, procedo en este trabajo a efectuar lo que me ha parecido más urgente: acometer la descripción codicológica del manuscrito y editar el texto. El objetivo primordial es, desde luego, dar a conocer su contenido para que pueda ser leído y analizado por los historiadores e investigadores especialistas en las corporaciones asistenciales de la España medieval, en general, y de la Corona de Aragón, en particular.

\section{Criterios de edición}

Para la presentación gráfica del texto he procurado seguir las indicaciones de algunos buenos manuales sobre escritos medievales y renacentistas. ${ }^{11} \mathrm{He}$ prestado bastante atención a las particularidades léxicas y morfológicas del aragonés del siglo $\mathrm{xv},{ }^{12}$ en especial las referentes a las especificidades del habla turolense. ${ }^{13}$ He tratado también de alejarme de forma absolutamente consciente del extremo paleografismo que afecta a muchas ediciones de textos de los siglos XV y XVI, pues no dudo en ofrecer las que son mis lecturas del documento, en consonancia con los nuevos tiempos de la edición de docu-

9 Hay una mención al «hospital de San Julián» en un testamento, otorgado en Teruel por Juan Domínguez de Perales y su esposa, María de Hungría, el 29 de marzo de 1348. Cf. Alberto López Polo, Catálogo del Archivo del Capítulo General Eclesiástico, Teruel, Instituto de Estudios Turolenses, 1965, p. 71. Agradezco a mi colega Raúl Villagrasa Elías que se pusiera en contacto conmigo personalmente para ofrecerme, de forma altruista, estos datos de su propia investigación, que queda citada en la nota siguiente.

10 Raúl Villagrasa Elías, La red de hospitales en el Aragón medieval (ss. XII-XV), Zaragoza, Institución «Fernando el Católico», 2016,pp. 141 y 151.

11 Me refiero a los trabajos de Alberto Blecua, Manual de crítica textual, Madrid, Castalia, 1983; José Manuel Fradejas Rueda, Introducción a la edición de textos medievales castellanos, Madrid, UNED, 1991; Miguel Ángel Pérez Priego, Ejercicios de crítica textual, Madrid, UNED, 2010; y Pedro SánchezPrieto Borja, Cómo editar los textos medievales. Criterios para su presentación gráfica, Madrid, Arco Libros, 1998.

12 Manuel Alvar, Estudios sobre el dialecto aragonés, Zaragoza, Institución «Fernando el Católico», I (1987), II (1998) y III (2002).

13 Javier Terrado Pablo, La lengua de Teruel a fines de la Edad Media, Teruel, Instituto de Estudios Turolenses, 1991. 
mentos de la Edad Media. ${ }^{14}$ La búsqueda de documentación en los repertorios lexicográficos más habituales, como los diccionarios de la Real Academia Española (DRAE) y de Autoridades (Autoridades),${ }^{15}$ se ha hecho casi siempre mediante la consulta en línea tanto de CORDE como del NTLLE. ${ }^{16}$ No he anotado de forma exhaustiva la mucha riqueza léxica y morfosintáctica del texto, pues es labor que queda pendiente para otra ocasión. Solo me he limitado a aclarar aquellas palabras o expresiones que pudieran presentar dificultades de comprensión al lector actual. En resumen, los criterios que se han utilizado para editar el texto son los siguientes:

- Se regulariza el uso de $i / j / y$, reservando $i$ para los valores vocálicos, mientras que $j$ / $y$ se reservan para los consonánticos.

- Se regulariza el uso de $v / u$, reservando $u$ para los valores vocálicos y $v$ para los consonánticos.

- Se resuelve en et la nota tironiana (\&), puesto que la grafía presente en el texto cuando no se usa la abreviatura es mayoritariamente esa, aunque ocasionalmente los escribas del siglo Xvi también se valgan de 'e' o incluso de ' $y$ '.

- Se resuelve el signo general de abreviación nasal como $n$, excepto las situadas en vocales previas a consonante bilabial ('b' o 'p'), que se hace en $m$, puesto que así aparece en bastantes ocasiones. De hallarse una $n$ delante de bilabial es porque así lo recogió el escriba, oscilación por otra parte muy frecuente en los textos de esta época.

- Se modernizan $r$ / rr y s / ss según su uso actual, en tanto que aparezcan en posición inicial o final de la palabra (dos y no doss; reverençia, y no rreverençia). Se respeta la consonante doble original en caso de estar situada en interior de palabra (onrra indistintamente de onra), además de en las terminaciones verbales de subjuntivo (fuesse indistintamente de fuese). En todos los demás casos se obvia la consonante geminada ociosa (fazemos y noffazemos; oficiales y no officiales; aceptar y no acceptar).

- Utilizo la tilde para distinguir formas verbales sin hache de las conjunciones y/o preposiciones actuales (é tenido / e tenido), y también para

14 Enunciados por José Manuel Lucía Megías, Elogio del texto digital, Madrid, Fórcola, 2012.

15 Diccionario de Autoridades, Madrid, Gredos, 1963, 3 vols.

16 CORDE: Corpus Diacrónico del Español: <http://corpus.rae.es/cordenet.html> [2017-11-15]. NTLLE: Nuevo Tesoro Lexicográfico de la Lengua Española: <http://buscon.rae.es/ntlle/SrvltGUILoginNtlle> [2017-11-15]. 
distinguir palabras con grafías ausentes (dó por doy). Asimismo, marco con tilde los pronombres personales apocopados cuando por su situación en la frase pueden inducir a error en su función sintáctica (nós [=nosotros] devemos / nos devemos).

- Se resuelven las contracciones mediante apóstrofo (d'estos, y no destos).

- Se utilizan los guiones oblicuos $(\backslash /$ ) para indicar una reconstrucción interlineal efectuada por el copista.

- La puntuación y la acentuación se realiza conforme a los criterios ortográficos actuales. Se resuelven las abreviaturas más habituales sin dejar constancia de ello. En caso de duda, se recurre a la anotación a pie de página.

- Los numerales romanos se transcriben conforme al orden romano, no al medieval (IV, y no iiij). El mismo criterio se aplica a la foliación en romanos del manuscrito.

\section{Edición del texto}

[5] Capítulo primo. De mantener la lámpara, a II.

Capítulo del convivio, a II.

Capítulo del conto ${ }^{17}$ que án de dar los mayordomos viejos a los nuevos, a III.

Capítulo del conto, a III.

Capítulo de los mandamientos, a IV.

Capítulo de confradre que enfermare de fuera de la ciudat, a IV.

Capítulo de cómo cada un [6] confradre á de dar XII dineros por cada un anyo, en memoria de ciertos Paternostres que cada uno es tovido ${ }^{18}$ de dar por confradre defuncto, a VI.

Capítulo de la misa de requiem del domingo siguiente que se dize por confradre defuncto, a VII.

Capítulo del mandant que muriere en casa de confradre, a VIII.

Capítulo de confradre que [7] fijo dexare de hedat, que sea cogido en esta companya, a IX.

17 conto] 'cómputo', es decir, balance económico de la cofradía.

18 tovido]. Participio de ‘tener' por analogía, frecuente en Aragón hasta que ‘tenido’ comenzó a imponerse a finales del siglo xv. En el texto que editamos conviven las dos formas. Cf. María Luisa Arnal Purroy y José María Enguita Utrilla, «Aragonés y castellano en el ocaso de la Edad Media», Aragón en la Edad Media, 10-11 (1993), pp. 51-84, especialmente p. 65. 
Capítulo de ir a velar confradre -o confradresa- que estudiere enfermo, a X. Capítulo de plegar a capítol en do el pelustre mandare, a X.

Capítulo de pelustre o mayordomos que por el sayón fueren amonestados de ir a velar o a soterrar, a XI.

Capítulo de quien favlare [8] sin la carta, a XI.

Capítulo de plegar del capítol, a XI.

Capítulo de quand fueren plegados a capítol, que aciendan una candela de tres dedos, a XI.

Capítulo de confradre que viniere a menos, a XII.

Capítulo de jugar a juego ninguno a sequas,,$^{19} \mathrm{a}$ XIII.

Capítulo que los mayordomos tengan los bienes de la conpanya, a XIII.

Capítulo de quien defendiere penyos, a XIV.

[9] Capítulo que si el mayordomo o el pelustre ovieren a fer camino, que sean tovidos dexar lugartenient, a XIV.

Capítulo de crecer en la carta, a XIV.

Capítulo de quien cayere judez, a XV.

Capítulo de la entrada, a XV.

Capítulo de quien beviere en taberna el día del sitio, a XVI.

Capítulo del que batiere la carta, a XVI.

Capítulo del banyar del defuncto, a XVII.

Capítulo de quien morrié fuera de la ciudat, que sea tenido dar por cada anyo XII dineros, a XVII.

[10] Capítulo de confradre que ha querella de otro confradre, dé V sueldos, a XVIII.

Capítulo de fijo de confradre que muriere de hedat de X anyos, a XVIII.

Capítulo que cada un confradre venga a misa el II domingo del mes, a XIX.

Capítulo de quien sacare guchiello ${ }^{20}$ pora otro, a XIX.

Capítulo de quien se mandare en orden, a XX.

Capítulo de quáles penas án de dar conto los mayordomos et de quáles no, a XXI.

[11] Capítulo de quien batiere la manda el día del sitio, a XXII.

Capítulo de quien entrare en esta companya, que sea tovido dar casa con penyos, a XXII.

19 sequas] 'secas', según la típica fluctuación de los diptongos aragoneses en -ua-. Cf. Emilio Alarcos, Fonología española, Madrid, Gredos, 1968, p. 223.

20 guchiello]. Forma medieval de 'cuchillo', cuya más temprana documentación se establece en el Fuero de Soria, a finales del siglo XII (apud CORDE). 
Capítulo de la licencia del oficial, a XXIII.

Capítulo qu'el demandador sea tovido dar conto por cada domingo e cada Paschua, a XXIV.

Capítulo del conto cómo se deve dar. Capítulo de cómo los mayordomos et hospitalero deven meter en seguro lo de la companya et espital. ${ }^{21}$

Capítulo del confrare que se saliese de la companya, XXIV. ${ }^{22}$

[12] Capítulo del que desonrrare adalgún oficial de la companya, XXVI.

Capítulo del que deshonrrare algún cofadre de la companya, XXVII.

Capítulo cómo se deven guardar todos los capítulos que en el presente son escriptos, XXVII.

Capítulo de cómo se deven nombrar oficiales de dicha companya, XXIX.

Capítulo de parar sitio en cada un año a toda la companya, un año día de Sant Julián y otro año día de Sant Bartholomé, ff. XXX.

Capítulo del clérigo que hará falta en su mesa el día de la missa,ff. XXX. Capítulo del que se llevare vianda ninguna el día que la companya comerá, XXII. [13] Capítulo de la ordenación de la cambra, XXXIII. ${ }^{23}$

Capítulo de los que querrán entrar cofadre, XXXIV

Capítulo si algún cofadre querrá part de la cambra de la dicha companya, XXXV.

Capítulo cómo deven nombrar los administradores de la dicha cambra, XXXVII.

Capítulo del que no querrá aceptar el oficio de la administración de la dicha cambra, XXXVIII.

Capítulo si algunos confadres querrán desfazer la dicha cambra, cómo se ha de regir, XXXVIII.

Capítulo qu'el espitalero tenga cargo del conto de la cambra, XL.

Capítulo que los doze nombren spitalero que sea útil y tomar seguro d'él, ídem, $40 .{ }^{24}$

[14] Capítulo qu'el mayordomo lleve cada domingo el libro de todos los confradoreses et confradoresas; y si no, peche X sueldos, XLI.

Capítulo de nombrar oficiales y de quien no querrá aceptar, XLII.

21 El texto está escrito en rojo, posiblemente un añadido posterior para aclarar el contenido del capítulo, pero de la misma época y mano que el texto principal.

22 A partir de éste, todos los capítulos del índice fueron añadidos por la mano F. Nótese, por ejemplo, el uso aquí del más moderno término confrare, en lugar de confradre, que es el predominante a lo largo del manuscrito.

23 Marginalia superior central] $\neg$ cambra $\neg$

24 OR: 40]. En arábigos, no en romanos. 
Capítulo de la pena de los cantores, XLIII.

Capítulo de la procesión del día de Santa Quiteria, ídem.

Capítulo del conto que deven dar los mayordomos, XLIV.

Capítulo qu'el conto que comerán día de Sant Julián se dé y que sea por todo el año desde henero, XLV.

Capítulo cómo se debe meter en seguro de la companya, XLVI. ${ }^{25}$

[17-Ir] Esta es la ordenación de la confradría de senyor Sant Julián, de la ciudat de Teruel.

En el nonbre del nuestro senyor Ihesu Christo et de la virgen Sancta María, su madre, et $a^{26}$ honor de todos los sanctos de Dios, en la era de mil et CCCC et XL, ${ }^{27}$ aquesta hermandat et aquesta companya establecen los [18-Iv] cofradres de senyor Sant Bartholomé et de Sant Julián de Teruel, en nombre et en advocació de Sant Bartholomé let Sant/ Julián, fazemos et ordenamos nuestras posturas segunt que d'aquí adelant es scripto et ordenado a fieldat ${ }^{28}$ del señor Rey de Aragón et $a^{29}$ hondra de la ciudat de Teruel. Et ordenaron las posturas que se siguen.

Capítulo primo: de mantener la lámpara.

[19-IIr] Primerament, prometemos mantener una lámpara que arda de noche et de día delant del altar del dito senyor Sant Julián.

\section{Capítulo del convivio..$^{30}$}

Otrosí establecemos que el día et fiesta del dito santo, que fagamos nuestro convivio todos los confradres ensemble,,$^{31}$ et que demos a comer a VI pobres assín como a nós mismos. Et qualquiere [20-IIv] confradre que otra cosa de comer aduxiere sobre taula, sino lo que los mayordomos darán, peche VI dineros. Et luego, otro día siguient, que fagamos nuestro capítol general et ordenemos el provecho de la conpanya, et pongamos mayordomos pora todo el

25 En blanco las páginas 15 y 16.

26 OR: ha]. Modifico el texto para adecuarlo a los criterios de edición y al uso actual de la preposición.

27 En el margen inferior central, la misma mano posterior que ha escrito los capítulos modernos del índice anota: «Año de 1402». En efecto, el texto está fechado en la era hispánica de 1440, año 1402 de la era cristiana.

28 fieldat] 'lealtad', 'fidelidad'.

29 OR: $h a$ ]. Modifico el texto para adecuarlo a los criterios de edición y al uso actual de la preposición.

30 convivio]. «La función a que es uno convidado; y especialmente se entiende por la comida o banquete» (Autoridades, s.v., 2).

31 ensemble]. «Juntamente, de in simul», como explica Francisco del Rosal en su Origen y etimología de todos los vocablos originales de la lengua castellana de 1611 (apud NTLLE). 
anyo, es a saber, un pelustre ${ }^{32}$ et dos mayordomos. Et el pelustre del anyo passado tome esta carta en la mano et dela al pelustre [21-IIIr] nuevo et a sus companyeros, los quales la companya avrán esleídos. Et tengan el oficio todo el anyo, dins ${ }^{33}$ pena de $\mathrm{X}$ sueldos jaqueses.

Del conto que án de dar los mayordomos viejos a los nuevos.

Otrosí, establecemos et ordenamos que del día del dito sancto al día de Sancta María de março, sean tenidos los mayordomos viejos a los nuevos de darles conto entro ${ }^{34}$ al dito día de [22-IIIv] todas las datas e receptas. E si no lo farán, que corran en pena de $\mathrm{X}$ sueldos por cada día que faldrá ${ }^{35}$ de no dar conto.

Del conto.

Ítem, establecemos que si los ditos mayordomos nuevos serán requeridos de tomar conto por los ditos mayordomos nuevos e no lo farán, que corran en pena de $\mathrm{V}$ sueldos por cada día que encorrerán de no recebir el dito conto, seyendo requerido por los [23-IVr] diltos mayordomos de suso ditos. E cualquiere confradre que rogara por aquestos, que corra en pena de II sueldos.

De los mandamientos.

Otrosí, establecemos que si algún confradre los mandamientos d'esta companya no observare, luego sea echado d'ella si non se repintiere. Enpero clamando mercés ${ }^{36}$ la companya, que le vala; et peche por la falta II sueldos.

[24-IVv] De confradre que enferme.

De a cabo, ${ }^{37}$ establecemos que si algún confradre d'esta companya enfermare o muriere fuera de la ciudat de Teruel, et a la dita ciudat se manda-

32 pelustre]. Parece ser una forma particularmente aragonesa del catalán 'prebost', que da 'preboste' en castellano y que deriva del latín 'praepositus', con sentido de 'jefe'. Cf. Joan Coromines, Breve

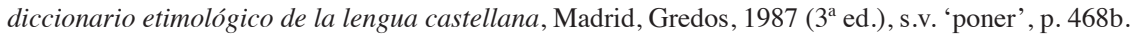

33 dins] 'bajo'. Es adverbio muy frecuente en el aragonés del siglo xv, en expresiones como «dins la forma siguiente» (cf. Serrano y Sanz, Documentos relativos de la pintura de Aragón, p. 33 apud CORDE).

34 entro] 'hasta' (Diccionario de la Real Academia 1791, s.v., apud NTLLE).

35 faldrá] 'faltará', bien documentado en textos como La fazienda de Ultramar o el Viaje de Juan de Mandevilla (apud CORDE).

36 mercé]. Es 'merced', con la típica pérdida de la 'd’ final típica del aragonés medieval. En este texto conviven ambas formas, con una ligera preferencia por mantener la interdental final. Cf. Arnal Purroy y Enguita Utrilla, «Aragonés y castellano en el ocaso de la Edad Media», p. 62.

37 De a cabo] 'a partir de ahora'. 
ra aduzir, que vaya nuestro pelustre con $\mathrm{X}$ companyones por el dito defuncto o enfermo. Et sean los ditos $\mathrm{X}$ de nuestros confradres, en tanto que puedan ir et venir al día. Et son los [25-Vr] mo/jones Alfambra, Elpovo, La Puebla, Vallacroich, Villel, Los Rodenales, Beças, Celha, Villarquinado. Et qualquiere de los companyeros que, por el pelustre o por el sayón, ${ }^{38}$ fueren amonestados et ir no $\hat{1}^{39}$ querrán, que pechen cada III sueldos. Et quando el dito cuerpo aduxieren, que lo salgamos a recebir todos los confradres a la puerta de la dita ciudat, por do el [26-Vv] cuerpo entrara; et el que no 1 fuere, que peche aquella misma pena. Et venido el cuerpo, que vayamos todos los confradres con él a su casa o allí do sus amigos tovieren por bien. Et quando el pelustre con sus X companyeros querrán ir por el enfermo o por el defuncto, que vayan con missión del mismo, si lo oviere; et si de lo suyo non lo oviere, que vayan con missión [27-VIr] de la companya. Et otrosí, fagan ordenadament la missión de la sepultura. Et el que no fuere al fer $^{40}$ de la fuessa ${ }^{41}$ que peche II dineros; et el que non fuere al soterrar, que peche VI dineros.

Capítulo de cómo cada un confradre á de dar XII dineros.

Otrosí, establecemos et ordenamos que cada confrade o confradressa sea tenido dar XII dineros por cada anyo en memoria de [28-VIv] cier/tos Paternostres que cada uno á de dar por los defunctos. E aquestos sea tenido de coger el almosnero ${ }^{42}$ que por la dita companya será esleído; e de la sobredita almosna se pague lo siguient: primerament, VI dineros para fazer la fuesa de confradre mayor; e de chiquo, IV dineros. Segundament, a cada uno de los que los levaran las andas, doblen dineros. Tercerament, que de la dita [29-VIIr] al/ mosna, si á visitado algún confradre pobre de la dita companya aviendo mandamiento por la dita companya, si lo avrá nescessario. Quintament, que quando los mayordomos viejos al día sobredito de Sancta María de março darán conto -segunt dito es-, que el dito almosnero viejo sea tenido de dar conto

38 sayón]. «Oficial subalterno de la administración de justicia» (DRAE, s.v., 3).

39 il 'allí', conforme al uso habitual de este adverbio en castellano procedente de la fusión de los adverbios latinos 'hic' e 'ibi'. Cf. Joan Corominas, Diccionario crítico-etimológico de la lengua castellana, Madrid, Gredos, 1954, IV, pp. 769-70.

$40 \mathrm{fer}$ ] 'hacer', conservando la 'f' inicial del latín facere, tal como era frecuente en el navarro-aragonés medieval. Cf. Arnal Purroy y Enguita Utrilla, «Aragonés y castellano en el ocaso de la Edad Media», p. 58.

41 fuessa] 'fosa', es decir, 'tumba'.

42 almosnero]. «Lo mismo que limosnero o amigo de hacer limosnas» (Autoridades, s.v.) 
segunt el día et las penas sobreditas al dito almosnero nuevo que posa/do [30VIIv] por la dita companya.

De la missa.

Ítem, establecemos que al confradre defuncto, que el domingo siguient todos los confradres le seamos tenidos dezir una misa de Requiem conventual por su ánima. Et qualquiere confradre que no í viniere seyendo amonestado, sea tenido de pechar la pena asín como por la sepultura. Et de que fuere dicha la mi/sa, [31-VIIIr] que salgamos sobre la fuesa, et después que vayamos con el clérigo que dirá la misa a render gracias a la casa del confradre defuncto. Aquesti ${ }^{43}$ mismo oficio sea fecho por las confradoresas et por las mulleres de los confradres defunctos.

De mandant que muriere en casa de confradre.

Otrosí, establecemos que si por aventura algún mandant muriere [32-VIIIv] en casa de confradre, que todos los confradres seamos al soterrar, dins la pena desús $s^{44}$ dita por el confradre. E si muriere de noche, non iríamos a velar. Et si toviere de qué, peche a la companya XII dineros et al sayón VI dineros. Et esto recapde el confradre do muriere; et si non lo recabdare, péchelo el confradre en cuya casa muriere el mandant. [33-IXr]

De confradre que fijo dexare.

Otrosí, establecemos que si algún confradre muriere et dexare fijo de hedat, sea cogido en esta companya dando una livra de cera. Et si fijo non dexare, su muller finque confradresa mientre mantuviere biudedat.

Capítulo de ir a velar confradre o confradresa.

Otrosí, establecemos que si algún confradre, o su muller, enfermare, [34IXv] que lo vayamos a velar cada noche dos confradres, si menester fuere. Et si más de dos confradres, II, oviere menester el pelustre í de enbiar ${ }^{45}$ enbíe tantos quantos menester í fueren. Et qualquiere que por el sayón fuere amo-

43 aquesti]. Demostrativo singular masculino acabado en -i, típico del navarro-aragonés medieval. Cf. Carmen Pensado, «Sobre la -i de algunas formas pronominales en los antiguos dialectos hispánicos», Boletín de la Real Academia Española, 64 (1984), pp. 143-170.

44 desús] 'encima', es decir, 'arriba' (DRAE, s.v.)

45 OR: omite]. Se restaura la más que probable errata del copista por omisión. 
nestado et ir no í querrá, peche IV dineros. Et si negare que non fuere amonestado, el sayón sea credido por su jura. Et si el sayón jurar non quisiere, peche la pena sobredita. [35/Xr]

Capítulo de plegar capítol.

De a cabo, establecemos que si por aventura, por algunos negocios, el pelustre mandara llegar los confradres, el sayón vaya a d'amonestar los que vengan et que se pleguen a do el pelustre mandara. Et si el sayón no trobare al confradre en su casa, dígalo a su muger, si la oviere, o a su mensatge. Et el que no í viniere, peche II dineros; et si fuere [36/Xv] amones/tado pora capítol et no í viniere, peche otrosí IV dineros. Et qualquiere confradre que fuere amonestado pora capítol general et no í viniere, que peche VI dineros.

De mayordomo que fuere amonestado.

Otrosí, establecemos que si el pelustre o los mayordomos pora vellar, o asoterrar, o a capítol, por el sayón fueren amonestados et non í vinieren, peche el pelustre XII dineros et sus companyeros cada VIII dineros. [37/XIr]

De quien favlare sin la carta.

De a cabo, establecemos que ninguno non sea osado de favlar en capítol sinon con la carta en la mano. Et si lo fiziere, peche cada vegada VI dineros et luego sean cogidos.

Del plegar del capítol.

Otrosí, establecemos que quandoquiere que el pelustre capítol quisiere plegar, diga al sayón en quál lugar se plegarán o en quál hora.

Capítulo de [38/XIv] cómo aciendan una candela.

De a cabo, establecemos que los primeros confradres que a capítol se plegaran exida de misa maitinal, quando fueren plegados $\mathrm{V}$ confradres, enciendan una candela de tres dedos. Et el confradre que amonestado fuere et non verná, peche IV dineros. Et si la candela quemada viniere, peche dos dineros.

De quien fuere amonestado de ir a velar o a soterrar. [39/XIIr]

Otrosí, establecemos que si algún confradre de esta companya, por algunos negocios, a capítol, o a velar, o a soterrar, o a qualquiere otra cosa, 
fuere amonestado por el sayón, et no í podrá venir, véngase $\mathrm{e}^{46}$ a escusar al pelustre et demándele licencia; et si non lo fiziere, peche por la falta XII dineros.

De confradre que viniere a menos.

De a cabo, establecemos [40/XIIv] que si por aventura algún confradre d'esta companya viniere a vegedat o a pobredat, o acaso que non avrá nada et non lo podrá ganar, mandamos que nuestro pelustre le dé vida convinent de los bienes de la conpanya, fasta que lo pueda ganar o que Dios lo tome a su part. Et si por aventura viniere a mengua por juego, non seamos tenidos de ayudarle en nenguna cosa. [41/XIIIr]

Capítulo de jugar a juego.

Otrosí, establecemos que ningún confradre non sea osado de jugar a ningún juego a sequas -exceptado a ballesta- et que no puedan prestar a onzenas. Et el confradre que lo fiziere, peche por cada vegada $\mathrm{V}$ sueldos el uno y el otro, et luego sean cogidos. Et el confradre que por él rogare, peche otro tanto; et sea creído por su jura el cofradre que lo veía. Et que sea tenido [42/XIIIv] de restituir lo que le avrá ganado al otro.

Capítulo que los mayordomos tengan los bienes.

De a cabo, establecemos que el pelustre et los mayordomos que tengan en su poder los bienes de la companya en lur ${ }^{47}$ tiempo, et pónganlos en escripto. Et recapden todas las otras cosas por guisa que buen conto den a la companya. Et si por culpa d'ellos algunas cosas se menosca/ban [43/XIVr] de la companya, que lo pechen ellos a la companya.

Capítulo de quien defendiere penyos.

Otrosí, establecemos que ningún confradre no sea osado de defender penyos nin revellar al sayón por qualquiere manera. Et si lo fiziere, que peche VI dineros. Et si al pelustre o a sus companyeros, peche XII dineros. Et si a la companya revella repenyos, peche V sueldos. Et si [44/XIVv] pechar non los quisiere, sea echado de la companya et nunqua í sea cogido.

$46 \mathrm{OR}]$ uengasse. Se corrige por ser un uso enclítico del pronombre 'se'.

47 lur] 'su', el típico posesivo del aragonés medieval. Cf. Enrique Pato, «Algo más sobre la historia del posesivo lur», Archivo de Filología Aragonesa, 66 (2010), pp. 13-32. 
De lugartenient.

De a cabo, establecemos que si el mayordomo, o el pelustre, o el sayón, por algunos negocios, ovieren a fer camino, que sean tovidos dexar lugartenient. Et si non lo fizieren, pechen por cada vegada XII dineros.

De crecer en la carta.

Otrosí, establecemos que los confradres d'esta companya [45/XVr] puedan en esta carta acrecentar capítoles a utilidat et provecho de la companya.

De quien cayere judez. ${ }^{48}$

De a cabo, establecemos que qualquiere confradre d'esta companya que cayere Iudex, sea tovido dar a esta companya un carnero que vala $\mathrm{V}$ sueldos. Et si almotaçaf, ${ }^{49}$ dé medio carnero o II sueldos. Et si oviere qualquiere otro oficio, o casare, sea tenido dar XII dineros pora un quarto. Et qualquie/re [46/XVv] confradre clérigo d'esta confradría $q u e^{50}$ oviere rectoría, o calongía, o vicaría, dé a esta companya un carnero que vala $\mathrm{V}$ sueldos. Et si misa cantare, de nuevo dé medio carnero o dos sueldos; et si evangelio, XII dineros pora un quarto. Et si fuere prior, medio carnero o dos sueldos. Et si mayordomo de capítol o terciero, dé XII dineros.

Capítulo de la entrada.

Otrosí, establecemos que [47/XVIr] qualquiere confradre que en esta companya querrá entrar, entre plaziendo a los companyeros et dé una livra de cera.

Capítulo del que beve en taverna.

Ítem, establecemos que ningún confradre non beva en taverna el día del sitio. ${ }^{51}$ Et si lo fiziere, peche VI dineros. Et si algo le acaeciere, non seamos tenidos de ferle oficio ninguno.

48 judez]. Se trata de la forma inicial en castellano de la palabra 'juez', en tanto que su origen etimológico estaba en el acusativo latino ‘judicem' (cf. Corominas, Breve diccionario..., s.v. 'juez’, p. 347b).

49 almotaçaf] 'almotacén' o 'zabazoque', derivado del árabe al-muhtasab (Corominas, Breve diccionario..., s.v. 'almotacén', p. 44a). Se trata del funcionario público que se encargaba de vigilar los pesos y las medidas que se usaban en los mercados medievales (cf. Pedro Chalmeta, La figura del almotacén en los Fueros y su semejanza con el zabazoque hispano-musulmán, Madrid, Universidad de Madrid, 1971). Para su papel específico en la ciudad de Teruel, véase Antonio C. Floriano, «Teruel en el siglo xv. La vida económica y la cuestión monetaria», Boletín de la Real Academia de Historia, 88 (1926), pp. 785-824, especialmente p. 790.

$50 \mathrm{OR}]$ omite que. Se restaura para completar el sentido de la frase.

51 sitio]. Se refiere al sitio general de la cofradía, es decir, el día que se celebraba la fiesta del patrón, en el que generalmente todos los cofrades comían y bebían compartiendo mesa y viandas. Cf. Pérez Pérez, «Las cofradías religiosas en la diócesis de Teruel»,p. 186. 
Capítulo del que batiere la carta.

Otrosí, establecemos et [48/XVIv] ordenamos que si algún confradre toviere esta carta en la mano, et por sanya la echare en tierra, peche XII dineros.

De quien falso testimonio ${ }^{52}$ fará.

Ítem, establecemos et ordenamos que todo confradre que falso testimonio fará a su cofradre, et provado 1 será, sea echado d'esta companya. Pero, clamando merced, que·l puedan perdonar pechando V sueldos; et luego le sean cogidos.

Capítulo de banyar el defuncto. [49/XVIIr]

Otrosí, establecemos que todo confradre que por el pelustre fuere amonestado de banyar o de adobar el cuerpo del defuncto, o de tomar el escanyo o de fer la fuesa, et non lo fiziere, que peche III dineros luego.

De quien morare fuera la ciudat.

Ítem, establecemos et ordenamos que qualquiere confradre que, por razón de ganados o de molinos, o por cualquiere otra manera, oviere a morar [50/ XVIIv] fuera de la ciudat de Teruel et non verná a velar o a capítol, que faga de restitución a la companya, por cada un anyo, XII dineros, porque los companyeros avrién dar fuera de la ciudat por qualquiere d'ellos, si menester fuere.

De quien se querellare de otro.

Otrosí, establecemos et ordenamos que qualquiere confradre que oviere querella de otro confradre por qual/quiere [51/XVIIIr] razón, non sea osado de querellarse a ninguno fasta que sea fadigado ${ }^{53} \mathrm{en}$ la companya. Et si el contrario fiziere, que peche por cada vegada XII dineros; et luego sean cogidos.

Querella de otro, dé V sueldos.

Ítem, establecemos et ordenamos que si algún confradre oviere querella de otro confradre d'esta companya, dé $\mathrm{V}$ sueldos ayuso, que la companya sean poderosos [52/XVIIIv] de entregar al querelloso. Et si se agravare, el rebel sea echado de la companya et no í sea cogido.

52 OR: testimoso]. Parece lógico considerarlo una errata, motivo por el que se procede a la restauración.

53 fadigado] 'tanteado', 'sopesado'. Cf. DRAE, s.v. 'fadigar', 1 y 2. 
De fijo de confradre de $\mathrm{X}$ anyos.

Otrosí, establecemos et ordenamos que si muriere fijo de algún confradre d'esta companya, et fuere de $\mathrm{X}$ anyos asuso ${ }^{54}$, que todos confradres lo vayamos a fer todo su oficio et a velar, como se contiene en capítulo. Et si de $\mathrm{X}$ anyos ayuso ${ }^{55}$ fuere, no'l seamos teni/dos [53/XIXr] sinon al soterrar, et no a otra cosa nenguna. Et el que no í fuere, peche IV dineros.

Que cada uno venga a misa el II domingo.

Ítem, establecemos et ordenamos que qualquiere confradre digo que sea de la dita conpanya sea tenido venir el segundo domingo del mes, segunt es ordenado por la dita companya, asín como los legos son tenidos de venir al dito domingo del dito mes, [54/XIXv] dins la pena del dito lego. Et si el dito clérigo no querrá venir al dito domingo, que sea tenido de pagar una misa o un sueldo; e asín los ditos legos, cada una misa o I sueldo

De quien sacare guchiello pora otro.

Ítem, establecemos et ordenamos que si algún confradre sacare guchiello pora otro confradre, sea echado de la companya. Et si clama/re [55/XXr] mercet, perche II sueldos et finque en la companya. Otrosí, si denostare a otro cofradre o pelea mesclare, peche por cada vegada XII dineros.

De quien se mandare enterrar en orden.

Ítem, establecemos et ordenamos que si algún confradre o confradresa de la dita companya se querrá enterrar de fuera de la ciudat en alguna orden, et mandara que le digan su misa en [56/XXv] la parroquia en do será vezino, aprés $^{56}$ que lo lieven a la dita orden, que non seamos tenidos de levarlo sino fasta la puerta de la ciudat, como es acostumbrado por los clérigos de capítol. Et si por aventura mandara que su oficio le fagan en la otra orden, primerament que seamos tenidos de levar el cuerpo a su parroquia a eferle ${ }^{57}$ oír un responso aprés levarlo fins ${ }^{58}$ a la orden e ferle [57/XXIr] su oficio complido,

54 asuso] 'arriba', es decir, de más de 10 años.

55 ayuso] 'abajo', es decir, de 10 años o menos.

56 aprés] 'después', uno de los adverbios con formas afines o coincidentes con el catalán típicos del lenguaje de Aragón en la Edad Media. Cf. Arnal Purroy y Enguita Utrilla, «Aragonés y castellano en el ocaso de la Edad Media», p. 68.

57 eferle] 'hacerle'.

58 fins] 'hasta', otro nuevo caso de coincidencia con el catalán. 
con tal condición que pague $\mathrm{V}$ sueldos a la companya por el esgasto ${ }^{59}$ que se fará de la cera. En otra manera, que non seamos tenidos a cosa nenguna.

De quáles penas án de dar conto los mayordomos.

Otrosí, establecemos et ordenamos que qualesquiere mayordomos que por anyo serán puestos por la dita companya, sean tenidos de secutar ${ }^{60}$ todas las penas que en los sobre/ditos [58/XXIv] capítoles serán trobadas, seyendo merecedor alguno de los confradres que aquellas puedan levar tro ${ }^{61}$ haver fin de paga a consellos de la dita companya. E de todas las penas que secutarán por todo el anyo sean tenidos de dar conto segunt el día et las penas sobreditas en el capítol tercero. Et receptado las penas que levaran por no ir al defuncto o a la defuncta, et de no ir [59/XXIIr] a misa et de no ir a capítol quando serán amonestados, de aquestas non sean tenidos de dar conto; ante, puedan ser a sus proprias voluntades de aquellas.

De quien batiere la manda el día del sitio.

Ítem, establecemos et ordenamos que qualquiere confradre que el día del sitio del Senyor Sant Julián, estando asentado a tavla en el convivio, no $s e^{62}$ agra/dare [59/XXIIv] de la vianda que en la dita yantar o convivio será dada a toda la dita companya, e si por qualquiere otra causa o sanya trosament ${ }^{63}$ la manda batiere en tierra, que peche $\mathrm{V}$ sueldos. Et el confradre que por él rogare, que peche X sueldos.

Capítulo de quien entrare en esta companya dé casa.

Otrosí, establecemos et ordenamos que qualquiere que en esta companya querrá [61/XXIIIr] entrar, sea tenido de dar casa con penyos. ${ }^{64} \mathrm{E}$ si no avrá casa con penyos e alguno la porná por él, que aquesti se segure del entrador a su propria voluntad, $\mathrm{car}^{65}$ si aquel faloria ${ }^{66} \mathrm{o}$ sendeira, ${ }^{67}$ que la dita casa con

59 esgasto] 'gasto'.

60 secutar] 'ejecutar'.

61 tro] «En nuestro lenguaje antiguo, lo mismo que hasta». Cf. Esteban de Terreros y Pando, Diccionario castellano (1767), s.v. apud NTLLE.

62 OR: nosse] Se corrige por tratarse del pronombre 'se' enclítico.

63 trosament] 'groseramente'.

64 penyos] 'prendas', aquí como sinónimo de garantías (DRAE, s.v. 'peños').

65 car] porque. Cf. Autoridades, s.v.

66 faloria] «Cuento, fábula, mentira» (DRAE, s.v.)

67 sendeira] Es voz portuguesa, que significa 'disparate', 'dislate' (http://www.dicio.com.br/sendeira/), reforzando el sentido de 'engaño' o 'mentira' que tiene en esta parte del texto. 
penyos sea tenido pagar la entrada, car el pelustre ni el mayordomo no curarán de demandar sino al que da casa con penyos.

Capítulo de la licencia del oficial. [62/XXIIIv]

Ítem, establecemos et ordenamos que, aviendo licencia de senyor oficial de la ciudat de Teruel, que el nuncio de la companya pueda sacar penyora ${ }^{68} \mathrm{o}$ penyoras de casa del clérigo confradre de la dita companya, asín como á poder de sacar del confradre lego dins la pena de suso contenida. [63/XXIVr] $]^{69}$

Qu'el demandador dé conto cada domingo.

Otrosí, establecemos et ordenamos que qualquiere demandador que puesto será por la dita companya sea tenido de render todo aquello que cogerá por cada domingo de Paschas, o otras fiestas o días que sean de demandar, qu'el otro demandador ${ }^{70}$ sea tenido de dar conto de la demanda que fará aquel día que demandara; e $s \imath^{11}$ por [64/XXIVv] aventura no lo fará, que corra en pena de XII dineros por cada un día que no lo fará.

Capítulo del confradre que se saliere de la companya.

Ítem, como a toda persona se expecte virtut de costancia et no tornar atrás de lo que promete et se obliga, et si el contrario fá,,$^{72}$ es razón que sea castigado; por tanto, ordenamos que si algún confradre d'esta companya, por alguna causa o ra/ zón $[65 / \mathrm{XXVr}]$ dixiere «no quiero estar d'esta companya», o «salirme quiero d'ella», que aquesti tal que semblantes paraulas ${ }^{73}$ dirá sea requerido con el sayón d'esa dita companya diziéndole que torne a la dita companya et se penida ${ }^{74}$ d'esas paraulas que avrá ditas. Et si aquel dirá al dito sayón que no quiere ser nin tornar,

68 penyora] 'prendas', 'empeños', aragonesismo por 'pignorar'.

69 La foliación en tinta roja y números romanos de la esquina superior derecha finaliza aquí, en el folio en el que además contiene un error (xxiij por xxiiij). No obstante, parece factible que la grafía ausente se deba al efecto de la guillotina sobre el pergamino a la hora de encuadernarlo. A partir de este folio comienza a aparecer una foliación en romanos, de mano posterior (finales del siglo xv), a tinta negra, que acompaña a la ya mencionada paginación moderna.

70 OR] La palabra 'mayordomo' aparece tachada con tinta roja antes de 'demandador'.

71 OR: assi] Se procede a la enmiendadel texto por errata del copista.

$72 \mathrm{fa}$ ] 'hace'.

73 paraulas] 'palabras'.

74 penida] 'arrepiente'. No he encontrado documentada esta palabra ni en CORDE ni en NTLLE ni en los demás repertorios de uso más frecuente. Sin embargo, Américo Castro, en sus Glosarios latinoespañoles de la Edad Media (Madrid, CSIC, 1991, p. 58), ya recogió las secuencias «penjtet, -bat, -tujt» como sinónimas de 'arrepentir', que parece ser el sentido que penida posee en esta y en otras ocasiones en que aparece en el texto. 
que por más descargo d'esa dita companya que gelo diga el pelustre de aque/lla [66/XXVv] que agora es o por tiempo será. Et si el dito confradre estará en su pertinación o su rebeldía como de primero, de no tornar a la dita companya, mandamos que el domingo aprés siguient de la última consultación o reqüesta fecha por el dito pelustre, la dita companya le faga dezir su misa conventual en su iglesia et parroquia, con sus candelas encendidas, et le lieven sus gracias [67/ XXVIr] a la puerta de aquel, así propriament como si fuesse muerto et sepelido. Et pague de pena a la dita companya por las espensas que fará XXX sueldos, por los quales sea fecha execución en vienes de casa de aquel por el pelustre de la dita companya, o por el juez de la dita ciudat, así como por debto et obligación, con carta iutgada, fecha et otor/gada $[68 / \mathrm{XXVIv}]^{75}$ por aquel $\backslash$ por el oficial eclesiástico pueda ser executado/ $/{ }^{76} \mathrm{Et}$ si caso será qu'el juez lo avrá a fazer, áya por su entrega et execución $\mathrm{V}$ sueldos, así como acostumbra fazer aver por entrega fecha en su cort con carta iutgada en bienes de algún debdor. ${ }^{77}$

Capítulo del que desonrare adalgún ${ }^{78}$ oficial de la companya. ${ }^{79}$

Ítem, queremos et hordenamos que si algún confradre, por fechos e cosas toquantes a esta companya, desonrará o dirá palabras injurio/sas [69/XXVIIr] al pelustre, o a los mayordomos, o al sayón, lo algún otro caballero d'ellos/ ${ }^{80}$ así en capítol como fuera de capítol, que por cada una vegada encorra en pena de $\mathrm{V}$ sueldos a bien levar.

Capítol del que desonrrare adalgún confadre. ${ }^{81}$

Ítem, asín mismo, queremos et hordenamos que si los mayordomos, o alguno d'ellos, o el pelustre, o el sayón, por fecho de la companya, en capítol o fuera de capítol, desonrara adalgún confradre, o le dirá palabras inj/uriosas [70/XXVIIv], que áya de pena, por cada una vegada, V sueldos; estos a bien levar, la qual pena sea para la companya.

75 Marginalia superior] capítol de quien desonrara (con letra de la mano F).

76 Anotación interlineal con letra de la mano F.

77 El manuscrito presenta a partir de aquí un claro cambio de mano, no solo por el hecho de que los capítulos dejan de escribirse en tinta roja, sino porque el tipo de letra varía, como se ha explicado más arriba.

78 adalgún] 'algún', con la típica variante aragonesa medieval de utilizar 'ad' por la preposición 'a' cuando la siguiente palabra comienza también por a-. Cf. Arnal Purroy y Enguita Utrilla, «Aragonés y castellano en el ocaso de la Edad Media», p. 70.

79 Título de capítulo con letra de la mano F.

80 Anotación interlineal con letra de la mano F.

81 Título de capítulo con letra de la mano F. 
Capítol tracta cómo devemos guardar todos los capitols que en esta regla son escriptos. $^{82}$

Ítem, ordenamos e queremos que todos los capitols de aquesta nuestra regla contenidos no nos obliguen a sagrament nenguno; mas sia/mos [71/XXVIIIr] obligados a pena pecuniaria, e aquesta bien levada por el pelustre et mayordomos. Todo aquesto sobredito e hordenado queremos que sea en nuestra companya observado e bien guardado. E aquel que lo guardara bien, de Dios e de la Virgen Sancta María avrá buen gualardo ${ }^{83} \mathrm{e}$ aquel que vidiere que no lo guarda bien, arrepiéntase de lo pa/sado [72/XXVIIIv] e guárdese $e^{84}$ de lo porvenir, porque la su ánima non sea traída en temptación. Amén.

E non se piensen los ditos confradres que son puestos de jus ${ }^{85}$ ley, mas son libres de jus la gracia de Dios e de la Virgen Sancta María, que ella sea rogadora a Dios por nós. Amén.

\section{Capítulo de cómo deven esleír ${ }^{86}$ oficiales ${ }^{87}$ [73/XXIXr]}

Ítem, por el poder a nosotros dado et atribuido por toda la dita companya, ordenamos que para el día de la fiesta de senyor Sant Julián, del mes de Jenero primero vinient que contará a Nativitate Domini Nostri Quinquagesimo tercio, ${ }^{88}$ et de allí adelant en cada I anyo, que XV días antes de la dicha fiesta echem et esliam oficiales para que en todo el anyo [74/XXIXv] rigan, procuren, administren durant su anyada subsiquient et complidament fins a la otra fiesta de senyor Sant Julián. Los quales oficiales son segund se sigue: son, a saber, primerament, XII regidores. Espitalero. Mayordomo. Pebostre. Cantores. Demandadores; ${ }^{89}$ et todos et qualesquiere otros oficiales necesarios a la dita companya. Et los quales, durant su anyo, cada uno sea tovido bien lealment [75/XXXr] et con grant diligencia haverse en su oficio. Et sean tovidos servir, regir, administrar cada uno su anyada conplidament, es a saber: de la

82 Título de capítulo con letra de la mano F.

83 gualardo] 'galardón', es decir, 'premio'.

84 OR: guardesse]. Se corrige por tratarse del uso del pronombre se enclítico.

85 jus] 'bajo'. Preposición muy frecuente del navarro-aragonés medieval, equivalente al castellano 'yuso' (cf. Alvar y Pottier, Morfología histórica del español, Madrid, Gredos, 1987, pp. 314-315).

86 esleir] 'elegir', otra variante léxica muy frecuente en el aragonés medieval como «evolución fonética popular frente al cultismo elegir» (Arnal Purroy y Enguita Utrilla, «Aragonés y castellano en el ocaso de la Edad Media», p. 73).

87 Título de capítulo con letra de la mano F.

88 La data referida aquí es la del año 1503.

89 El copista utilizó en esta parte del texto calderones de color rojo para separar los nombres de los oficiales mencionados. 
fiesta de senyor Sant Julián fasta la otra fiesta subsiguient inclusive. En manera que cada uno de los ditos oficiales rig $a n^{90}$ et sirvan su anyo complidament.

\section{Capítol de parar sitio.91}

Ítem, ordenamos que en cada un anyo d'aquí avant se pare un sitio a toda la companya de [76/XXXv] pan, vino et carne, et de otras cosas necesarias segund dito es; empero que se pare un anyo en el día de Sant Barthomé, del mes de agosto, et luego, en el otro anyo subsiguient, que se pare en el día de Sant Julián, en el mes de jenero.

Capítulo del clérigo que fará falta en su mesa [el] ${ }^{92}$ día de la misa.

Ítem, ordenamos que qualquiere clérigo de aquesta companya, ateniendo la mesada de dezir la misa ordinaria cada domingo [77/XXXIr] en la ermita de Sant Julián; et el día que fallirá áya de pena $\mathrm{V}$ sueldos: los tres sueldos pora·l espital et los \otros dos/ sueldos pora el mayordomo et espitalero. Et que sea tovido de emendar otro día la misa; et que si no la emendara, que áya aquella misma pena compartida \otra/ ves. Et así matex,$^{93}$ al mayordomo de los clérigos sea tovido de enbiar $[\ldots]^{94}[78 /$ XXXIv en blanco $]$

[79/XXXIIr] Capítulo del que se llevare vianda d'enguna.

De nuevo ordenamos que el día que la companya comerá, si alguno se llevará vianda, que peche $\mathrm{V}$ sueldos. Et si algún confradre rogare por él, que peche diez sueldos, y esto sin nenguna remisión. [80/XXXIIv en blanco].

[81/XXXIIIr] Capítulos de la ordenación de la cambra que se faze en el Spital de senyor Sant Julián et de senyor Sant Bartholomé.

Ítem, primerament hordenamos que cada un confadre de aquesta sancta companya séannos tenidos a dar una fanega de trigo neto et limpio, de dar et de tomar. Et el confadre o confadres que non ternán trigo [82/XXXIIIv] que

90 OR: rigam]. Se corrige la que parece ser una evidente errata.

91 De nuevo volvemos a encontrar el uso de tinta roja para los subtítulos de todos los capítulos, a partir de este y hasta el final del manuscrito.

92 OR: om.] Se restaura el artículo, error del copista por supresión, puesto que sí figura en el enunciado de este mismo capítulo que se puede leer en el índice.

93 OR: assi matex] 'asimismo'.

94 El texto presenta aquí una laguna, encontrándose en blanco lo que serían las tres o cuatro últimas líneas de este folio, el 31r, y todo el que sería el 31v. El texto se retoma, como la numeración, en el siguiente folio. 
puedan dar et sían tenidos a dar un fiador, para que por él sía compartida una fanega de trigo. Et aquesto sía cullido et pagado fasta el día de Sant Bartholomé del mes de agosto primero vinient. Et si pasado el dito día alguno o alguos avrá que non áyan dado la dita fanega de trigo, ${ }^{95}$ aquellos puedan seyer [83/ XXXIVr] penyorados, o convenidos, o en qualquier otra forma una vegada, et muchas, fasta aver restituido la dita part pertenescient a él o a ellos; et sían tenidos pagar qualquier misiones que por la dita companya se farán. Pero si î primero darant de los doze, o la mayor parte d'aquellos, et si por los doze o la mayor part non querrán pagar, [84/XXXIVv] sían convenidos daván justicia, seguns es dicho de suso, etcétera.

Capítulo de los que querrán entrar confradres en aquesta companya.

Ítem segundo, ordenamos que de oy avant qualsequiere persona o personas que querrán entrar confradres en aquesta sancta companya, sían tenidos dar menos de la entrada una fanega de trigo [85/XXXVr] para comprar la dita fanega de trigo; et encara que dé la entrada, tenga tiempo a pagar seguns ordenación et costumbre antiga de la dita fanega de trigo, no áyan tiempo antes aquella luego: aun restituyan dentro de quinze días aprés de entrado justa obligatión et convenimiento que en el primero capítol [86/XXXVv] es mencionado. Et en otra forma, no pueda seyer acogido ni acogidos, etcétera.

Capítulo tercero. Si algún confradre querrá part de la cambra.

Ítem tercero, ordenamos que aprés fecha la cambra et acomplido todo el pan en uno, algunos confradres avrán menester entre anyo de dito pan que aquel o aquellos allí vieran meter en segund [87/XXXVIr] aquella persona que por el dito espital et companya terná el cargo del dito trigo et aprés por aquello que tomara, complido el tiempo, pueda no pagando deván de los docze, o la mayor part de aquellos seyer convenido o convenidos et por mandamiento puedan seyer penyorados et las penyoras rendidas a tercero día. Et si por los doc/ze [88/XXXVIv] o la mayor parte non querrán fazer la razón, que en tal caso puedan seyer convenidos devant ${ }^{96}$ del juez \o del oficial clérigo/ et levados a toda execución fasta seyer contento el dicho administrador. Et en tal caso, los ditos XII o la mayor parte non puedan dar tiempo nenguno nin áyan

95 Siguen tres palabras ilegibles, que fueron borradas en la época y de las que no he podido extraer el significado.

96 devant] 'delante', claro catalanismo procedente de 'davant' (cf. Corominas, Breve diccionario..., s.v. 'delante', p. 203b). 
tal poder por tal que la dita canbra siempre aumente et non deminuyere, et [89/ XXXVIIr] áyan a responder por fanega, etcétera.

Capítulo quarto: cómo deven esleír los administradores.

Ítem quarto, ordenamos que los docze o la mayor part de aquellos puedan eleír ${ }^{97}$ un confradre o o dos que tengan cargo de la dicha adminstración del dicho trigo et dar buen conto et razón de aquel. Et aprés que por los dichos docze o la mayor part serán electo [90/XXXVIIv] o electos, el dicho administrador o administradores, aquestos sían tenidos meter en seguro al dicho spital et companya de la dicha acomanda del trigo et administración de aquel, et en aquella levar bien et lealment, et non parcial. Et si caso que el confadre o confadres o administradores el contrario fazían, en tal caso, por los dichos XII o la mayor parte, los [91/XXXVIIIr] pueda seyer dada en el dicho su anyo un conjunto con ellos que adminstre, etcétera.

Capítulo V: de los que no querrán aceptar el oficio de la adminstración.

Ítem quinto, ordenamos que aprés electo o electos el dicho adminstrador o adminstradores, que aquel día qu'ellos que tal oficio o adminstración no querrán en sí [92/XXXVIIIv] ac/ceptar, que aquel o aquellos, et cada uno de aquellos, encorra ${ }^{98}$ en pena de trenta sueldos, et que la dicha pena o penas sían para las necesidades del dicho espital, etcétera.

Capítulo VI: si algunos confrades querrán desfazer la dicha cambra, cómo se án de regir.

Ítem sexto, ordenamos que si en algún tiempo por [93/XXXIXr] algunos confadres u la mayor parte de la companya quisiesen dezir o dixiessen que la dicha canbra no querían, antes que se desbaraten,${ }^{99}$ aquello non se pueda fazer por nenguna manera ni maña, si ya por capítol general no seyendo todos colocados et nenguno no sea discrepante. Et si en el dicho capítol general la dicha cambra desfazía, que en tal caso [94/XXIXv] to/do el dicho pan, trigo o panes que en la dicha cambra avrá se vendan, et que los dineros que de aquel pan o panes saldrán non se puedan dividir ni partir por confadres ni por iguales partes; antes, sían puestos en rendas et sensales ${ }^{100}$ et aumentadores pora el dicho spital sobre propiedades foreras, franquas et quitas, etcétera.

97 eleir] 'esleír', 'elegir'.

98 encorra] 'incurra'.

99 OR: desbarates] Se procede a la restauración para concordar con el sentido de la oración.

100 rendas \& sensales] 'rentas' y 'censales'. 
Capítulo VII: en cómo [95/XLr] el spitalero tenga cargo del conto de la canbra. Ítem séptimo, ordenamos qu'el dicho electo o administrador sía el spitalero que oy es, o por tiempo será. Et si án con ellos mayordomos, que le ayuden. Pero el dicho spitalero sía tenido a dar conto et razón del dicho trigo, et no otri ${ }^{101}$ sinon tan solament quando le ayuden a plegar el pan [96/XLv] a la dicha canbra. Et visto el cargo que tenemos, que de oy avant se puedan í tornar a echar de los que han servido ya en los anyos pasados, etcétera. Et áyan de sabido, por el treballo que avrán para una yantar, quinze sueldos en cada uno anyo.

Capítulo décimo: ${ }^{102}$ en cómo los docze sían tenidos de esleír spitalero.

Ítem décimo, ordenamos [97/XLIr] que los docze que oy son, o por tiempo serán, sían tenidos a esleír spitalero que sía ombre útil et suficient pora la dicha administración et tomar seguro de aquel. Et si caso vinía que por el dicho electo por ellos, o la mayor parte d'ellos, aquel administrava mal et no dava conto ni razón de lo que recibrá posinventario con aquellos gravios seguns consta [98/XLIv] en el capítol tercero, que en aqueste tal caso todos los docze, et cada uno por sí, sían tenidos a los danios et menoscavos que por el dicho administrador en la dicha canbra o acomanda se fará.

Ítem, ordenamos ${ }^{103}$ que el mayordomo que es, o por tiempo será, que lieve cada domingo el libro, por que ofrezcan los que querrán. Et si non se levara, que peche III sueldos, aplicados para necesidades del spital. [99/XLIIr]

De esleír oficiales et del que no quiera aceptar.

Ítem, stablescemos et ordenamos que cada et quando et toda hora que aquesta conpanya ordenara et mandara plegar capítulo, que el mayordomo faga monir ${ }^{104}$ a los confradres. Et el confradre que sía monido et no í deverná, ${ }^{105}$ que peche de pena XII dineros. Et como serán plegados, que puedan a su buen arbitrio esle/ír [100/XLIIv] los oficiales: primerament, XII regidores; espita-

\footnotetext{
101 otri] 'otro'.

102 El salto de capítulos, del VII al X, indica con claridad que el códice ha perdido algunos folios en esta parte.

103 OR: ordenaros]. Se procede a la restauración por parecer evidente la errata del copista, dado que el uso de la primera persona del plural es una fórmula básica de escritos legales como el que se edita aquí.

104 monir] 'avisar', 'advertir', en el sentido de 'congregar'. Es un latinismo procedente de monere, documentado ya durante el siglo XIII en un texto tan emblemático como el Fuero de Zamora (ed. Castro-Onís, p. 37, apud CORDE).

105 deverná] 'vendrá'.
} 
lero; mayordomos; pelustre; cantores; demandadores; et qualesquiere otros oficiales necesarios a la dicha companya. Los quales durant su anyo sean tovidos ${ }^{106}$ bien et lealment, et con grand diligencia haverse en su oficio. Et aquel que por la companya será esleído et no lo querrá aceptar, que [101/XLIIIr] pague de pena XXX sueldos pora el hospital de la dicha companya,${ }^{107}$ de la qual pena no le sea havida mercet ninguna. Et qualquiere que rogara por él, que page la dicha pena.

De pena de los cantores.

Ítem, ordenamos et stablescemos que los cantores que serán esleídos por la dicha companya, et si no viniere cada domingo a oficiar, que pague de pena quatro dineros, los dos dineros pora los cantores [1020/XLIIIv] et los otros dos dineros pora·l ospital; et estos a bien levar.

Capítol de la procesión del día de Sancta Quiteria.

Ítem, stablescemos et ordenamos que todos anyos, en cada un anyo, seamos tovidos et obligados el día de Sancta Quitheria, del mes de mayo, de fazer huna procesión primerament a Sancto Domingo, que es camino de Valencia, et de allí a Sancta María de Castialvo, et de allí a Sancta María de Villespén, que les/ en la vega de la dicha ciudat; [103/XLIVr] et que vayamos todos confrades en toda la dicha procesión. Et el confrade que no í deverná, que pague de pena dos sueldos et seis dineros jaqueses, de la qual sean los VI dineros pora los mayordomos de la conpanya et los dos sueldos pora 1 hospital. De la qual dicha pena no sea havida merced ninguna, et ningún confrade non sea gosado $^{108}$ de rogar por él; et el que rogara por él, que pague la dicha pena sin [104/XLIVv] remedio alguno.

Capítol del conto que deven dar los mayordomos.

Ítem, otrosí ordenamos et establescemos que los mayordomos que oy día son, o por tiempo serán, sean tenidos dar conto de su administración desde el día del sitio, contando así: que el anyo que comerán al día et fiesta de senyor Sant Bartolomé del mes de agosto, sea tenido a dar conto fasta XV días del mes de septiembre aprés siguient. [105/XLVr] 
Ítem, ${ }^{109}$ asimismo el anyo ${ }^{110}$ que comerán el día et fiesta de senyor Sant Julián sean tenidos dar conto et razón fasta por todo el dicho mes de genero et ocho días del mes de febrero aprés siguient. Et de allí avant, el mayordomo o hospitalero viejo encorra en pena por cada un día que será requerido de dar el dicho conto et aquel no dará, et restituirá a los mayordomos et hospitalero nuevos, es a saber, de diez sueldos. Et asín mismo, si los dichos mayordomos vie/jos [106/XLVv] et hospitalero requieran a los dichos mayordomos et hospitalero nuevos que tomen el conto, et si aquel no querrán tomar, por cada día que el contrario farán, los dichos mayordomos et hospitalero encorran en la dicha pena. Et que en aquestas dichas penas, qualquiere que rogara por ninguno d'ellos corra en pena de dos sueldos, et así aquesto a los doze o a qualquiere d'ellos como a qualquiere otro confradre d'esa conpanya. Et aquesto porqu'es hun [107/XLVIr] gran danyo et perdimiento et diminución del dicho hospital et companya. Et asimismo, los contadores, o alguno d'ellos, en aquel día que el conto se dará distinrán o distinrá, que encorran o encorra en la dicha pena de dos sueldos. Et qualquiere que rogare por ninguno d'ellos, que encorra en la dicha pena como de suso dicho es; et sean las dichas penas pora 1 hospital, etcétera. Et asimismo, dins la sobre dicha hordenación et penas se entiende a [108/XLVIv] qualsequiere otro confradre o confradesa que tenga de administración \de la companya et hospital/. ${ }^{11}$

Capítulo cómo se deven meter en seguro lo de la companya.

Ítem, otrosí establecemos et ordenamos que, aprés dado el conto por los mayordomos et hospitaleros viejos, et serán cargadas las restas, si avrá a los mayordomos et hospitalero nuevos que de allí avant los XII electos de la companya no puedan dar nengunt conto; et si lo dan, que aquel no sea valedero, por tal que es grand danyo del dicho hospital. Et si aquestos por sí darán conto, que aquel [109/XLVIIr] sea nulo; antes sía a cargo de los dichos mayordomo e el hospitalero que atales rentas o recargas ternán cargadas. Et que los mayordomos et hospitalero, aprés que le serán cargadas las dichas recargas, aquellos sean tenidos de meterse en seguro de los dichos tenidos e recargas. Et si no lo fazen aquellos, de allí avant tengan a cargo suyo e áyan a dar fin e paga dentro de un mes jus la pena sobredicha. [110/XLVIIv ] ${ }^{112}$

109 Marginalia] «Qu'el año que comienza siguient, el día de señor Sant Julián se dé qüenta para todo el mes de henero». Letra de la mano F.

110 OR: añyo]. Se restaura la curiosa errata.

111 El añadido interlineal es letra de la mano F.

112 En este folio comienza una tercera mano de copista, correspondiente a un capítulo y una ordenación añadidos en 1524 
Capítol de cómo los seis son tenidos el día de la misa conventual a cobrar los medios esqueros.

Ítem, que los seis son tenidos, mayordomo e ospitalero, sean tenidos de ir el día de la misa conventual, luego enpués de misa, a coger los medios esqueros y esqueros ${ }^{113}$ de los que no havrán, y de confrades y de las cofradiesas. Si aquel día no podrán, vayan otro día que ellos querrán; y esto dentro de ocho días. Si no fueren, que queden solos los esqueros y medios esqueros a cargo de los seis, y hospitalero y el mayordomo se les juren, con el casero de la casa, dentro de fuero de ocho días.

\section{Ordenación.}

A XXV del mes de agosto, anyo mil quinientos veinte y quatro, teniendo capítol general el día de la misa conventual, fue concordado por todos, e todos concordes y nenguno discrepante, que cada un cofadre pueda servir y sea tenido de servir dos oficios de canbrero y spitalero, o mayordomo y spitalero. Y que del un [111/XLVIIIr] oficio al otro haya de vaquar tres anyos; y si pasados los tres anyos no lo querrá seyer, que pague de pena treinta sueldos. Y que nengún oficio de las cequias, hobrero ni regatero no lo pueda escusar, sino que sea spitalero, canbrero o mayordomo de otras companyas, que lo tal lo tenga por scusado.

Testigos fueron presentes el venerable mosén Johan, maestro, y Francisco Pérez, labrador, judgada, etc.

\section{Ordenación.}

A ocho días del mes de jenero, anyo mil quinientos veinte y nueve, plegado en principal de los confadres de la companya, enpués de la misa conventual, ordenaron que qualquiere que havrá seído mayordomo, spitalero o canbrero, y después verná por derecho que sabrá cualquiere otro oficio y no aceptara el dicho oficio, que encurra en pena de diez sueldos, y no más. Y si no havrá servido nengún oficio, que tenga de pena treinta sueldos, como antiguamente se acostumbrava de pagar.

Mosén Johan, maestro espitalario, y Francisco Pérez. [112/XLVIIIv]

113 medios esqueros y esqueros]. El 'esquero' es una «bolsa de cuero que solía traerse sujeta al cinto, y servía comúnmente para llevar la yesca y el pedernal, el dinero u otras cosas» (DRAE, s.v.) La evidente metonimia continente-contenido parece apuntar a una especie de pago de dinero que se efectuaba el día de la misa conventual, pero no he podido hallar más datos al respecto. 
Un manuscrito medieval aragonés inédito en la biblioteca de UCLA: la Ordenación...

Ordenación.

A XII de jenero del anyo mil quinientos cinqüenta y uno, teniendo capítol general en el día del senyor Sant Julián, fue concordado e mandado [...] $]^{114}$ [113/XLIXr] ... - la en la casa y no en la ciudat, so pena de cinquo sueldos.

\title{
Ordinación.
}

A X de enero del anyo MDLVII, establecieron todos los confradres conformes que el día de Sant Vicente en cada un anyo los oficiales que son -o por tiempo serán- y tuvieren administración [...] companya áya de dar y den licencia con pago del spitalero; y el cambrero áya de dar de todas las obligaciones y censos í venidas, so pena de perder el salario que por esto facen dar. Y ansí mesmo, nos lo pueda donar de su administración e sea sacado de su oficio; e si lo haze, sea de ninguna cor... [114/XLIXv].

A veinte y ocho días del mes de agosto del año contado del nascimiento de nuestro señor Jesús Christo de mil quinientos setenta y quatro, en capítulo general todos los confadres conformes, ordenaron que de oy adelante haya de haver en el granero dos llaves: la una haya de tener uno de los seis en capítulo y la otra el cambrero. Y el dicho seis tenga dicha llave hasta el día de Santas Cruces de mayo, y dicho día dé y restituya la dicha su llave a el dicho cambrero asta el día que dure la casa del spitalero o cambrero. Y así sea de aquí en adelante, lo qual se ordenó por voluntad de muchos de los confrades, que se podía consejar por que sea visto que el día de Santa Quiteria se ordena e faga conto para lo que conbiene a la compañía [... $]^{115}[115 / \mathrm{Lr}]$

\author{
$[\ldots]^{116}$ \\ Rodrigo Galán. \\ Quesada. \\ Per Antón. \\ Gallego.
}

114 El resto del folio, unas 12 líneas, está ilegible debido a que el pergamino ha corroído la tinta hasta hacerla lábil y borrosa. He solicitado permiso para realizar una reproducción hiperespectral de todos estos folios finales del manuscrito, con el objetivo de poder acercarnos en el futuro lo máximo posible a su contenido.

115 Las dos últimas líneas de este folio son, otra vez, ilegibles.

116 Figura aquí, en el recto del folio de guarda final, una lista de nombres, de la cual reproduzco los que puedo leer en la actualidad (todos menos el que figura en la primera línea), a la espera de nuevo de aplicar técnicas de imagen hiperespectral al manuscrito. 


\author{
Ángel de Villasar. \\ Johan Martínez de Arosa. \\ Morador. \\ Galçerán Pérez. \\ El fillo de Miguel de la Vega. \\ Pedro Sancho. \\ El fillo del Vayo.
}

\title{
4. Referencias bibliográficas
}

Alarcos, Emilio (1968), Fonología española. Madrid, Gredos.

Alvar, Manuel (1987-2002) Estudios sobre el dialecto aragonés. Zaragoza, Institución «Fernando el Católico», I (1987), II (1998) y III (2002).

Alvar, Manuel y Bernard PotTier (1987), Morfología histórica del español. Madrid, Gredos.

Arnal Purroy, María Luisa, y José María Enguita Utrilla (1993), «Aragonés y castellano en el ocaso de la Edad Media», Aragón en la Edad Media, 10-11 (1993), pp. 51-84.

Autoridades: Diccionario de Autoridades. Madrid, Gredos, 1963, 3 vols.

Blecua, Alberto (1983), Manual de crítica textual. Madrid, Castalia.

Castro, Américo (1991) Glosarios latino-españoles de la Edad Media. Madrid, CSIC.

CAstro, Américo y Federico de Onís (1916) Fueros leoneses de Zamora, Salamanca, Ledesma y Alba de Tormes. Madrid, Centro de Estudios Históricos.

Corominas, Joan (1954) Diccionario crítico-etimológico de la lengua castellana. Madrid, Gredos. 4 vols.

Corominas, Joan (1987) Breve diccionario etimológico de la lengua castellana, Madrid, Gredos ( $3^{\text {a }}$ edición).

CORDE: Corpus Diacrónico del Español: <http://corpus.rae.es/cordenet.html> [201711-15].

DRAE: Diccionario de la Real Academia Española. Madrid, Espasa-Calpe,1992.

FAlCón PÉrez, M. a Isabel (1997) Ordenanzas y otros documentos complementarios relativos a las corporaciones de oficio en el reino de Aragón en la Edad Media. Zaragoza, Institución «Fernando el Católico».

Faulhaber, Charles B. (dir.) PhiloBiblon - BETA: Bibliografía Española de Textos Antiguos. Base de datos de libre acceso en Internet: < http://bancroft.berkeley.edu/ philobiblon/> [2017-11-15].

FERRARI, Mirella (1991) Medieval and Renaissance Manuscripts at the University of California, Los Angeles. Ed. R. H. Rouse. Berkeley-Los Ángeles-Oxford, University of California Press. 
FLORIANO, Antonio (1926), «Teruel en el siglo xv. La vida económica y la cuestión monetaria», Boletín de la Real Academia de Historia, 88 (1926), pp. 785-824.

Fradejas Rueda (1991), José Manuel, Introducción a la edición de textos medievales castellanos. Madrid, UNED.

López Polo, Alberto (1965) Catálogo del Archivo del Capítulo General Eclesiástico. Teruel, Instituto de Estudios Turolenses.

Lucía Megías, José Manuel (2012), Elogio del texto digital. Madrid, Fórcola.

Navarro Espinach, Germán (2014) «Las cofradías medievales en España», Historia 396, 4.1 (2014), pp. 107-133.

NtLle: Nuevo Tesoro Lexicográfico de la Lengua Española. Base de datos de libre acceso en línea: <http://buscon.rae.es/ntlle/SrvltGUILoginNtlle> [2017-11-15].

PAто, Enrique (2010), «Algo más sobre la historia del posesivo lur», Archivo de Filología Aragonesa, 66 (2010), pp. 13-32.

Pensado, Carmen (1984), «Sobre la -i de algunas formas pronominales en los antiguos dialectos hispánicos», Boletín de la Real Academia Española, 64 (1984), pp. 143-170.

PÉrez PÉrez, Isabel (2008), «Las cofradías religiosas en la diócesis de Teruel», Revista de Historia Jerónimo Zurita, 83 (2008), pp. 161-198.

Pérez Priego, Miguel Ángel (2010), Ejercicios de crítica textual. Madrid, UNED.

Rosal, Francisco del [ca. 1611], Origen y etimología de todos los vocablos originales de la lengua castellana. Madrid, Biblioteca Nacional de España, MSS/6929.

SÁnchez-Prieto Borja, Pedro (1998), Cómo editar los textos medievales. Criterios para su presentación gráfica. Madrid, Arco Libros.

SERRAno y SAnz, Manuel (1917), Documentos relativos de la pintura de Aragón. Madrid, Tipografía de la Revista de Archivos, Bibliotecas y Museos.

Tello Hernández, Esther (2013), Aportación al estudio de las cofradías medievales y sus devociones en el reino de Aragón. Zaragoza, Institución «Fernando el Católico».

Terrado Pablo, Javier (1991), La lengua de Teruel a fines de la Edad Media. Teruel, Instituto de Estudios Turolenses.

Terreros y PAndo, Esteban de (1787), Diccionario castellano con las voces de ciencias y artes y sus correspondientes en las tres lenguas francesa, latina e italiana. Madrid, Imprenta de la Viuda de Ibarra y Compañía. 4 vols.

Villagrasa Elías, Raúl (2016), La red de hospitales en el Aragón medieval (ss. XIIXv). Zaragoza, Institución «Fernando el Católico». 